\title{
Outcomes of Information: An Analysis of Spiritual Messages
}

\author{
Jarkko Kari*
}

\author{
Department of Information Studies and Interactive Media, 33014 University of Tampere, Finland
}

\begin{abstract}
This article explores the outcomes of spiritual information via publications containing such information. Outcome of information is defined as any process that ensues from receiving a message, and the defining feature of spiritual information is that it is perceived as a message originally provided or received by extraphysical means. Finnish publications reportedly produced by means of a spiritual method were sought out. As a result, 109 documents ranging from the 1940 s to the 2000 s were obtained, processed and analyzed. The qualitative data analysis was carried out inductively, following the tenets of the interpretivist methodology. The data suggested that spiritual information is of great significance in all contexts, especially in everyday life, albeit there were also outcomes that can be regarded as trivial. The main result of the analysis is the discovery of five types of information outcome: processing, dispositions to, communicating, using, and effects of information. These types are also categorized at a general and specific level, yielding more detail about the concepts. The real contribution of this study is that it pulls together a multitude of various outcomes of information, and organizes them into a coherent, holistic typology. In so doing, the conceptual structure simultaneously implies that research areas which have earlier been considered as separate (e.g. information use and information sharing) can in actual fact be connected, if there is just a will to do it.
\end{abstract}

Keywords: Outcomes of information, spiritual information, processing information, dispositions to information, communicating information, using information, effects of information.

\section{INTRODUCTION}

A vast number of studies has been carried out on the production, organization and seeking of information. The underlying purpose seems to have been the facilitation of access to the right kind and amount of information in the right situation. But what is the ultimate rationale for all this? Surely information is not the be-all and end-all to those who actually interact with it. I would propose that the outcomes of information are more important than the information itself. If information does not lead into anything, it is a waste of space and time. It is baffling, however, how little attention the outcomes of information have received. Maureen McCreadie and Ronald Rice [1, p. 60] testify to this observation as follows: "The outcomes facet of the information seeking process, though implied in discussions of access to the value or benefit of using information, is rarely examined explicitly in research on information seeking."

To worsen the circumstances still, there seems to be broad variation in how to demarcate the topic. On the one hand, it is not only information (e.g. [2]) whose outcomes have been studied. They have also been linked to the output of information systems [3], information projects and activities [4], information behaviour [5], using a health Web site [6], information seeking [7], using information [8], and applying an idea [9]. These phenomena are, of course, closely related to information, but they are not information per se. On the basis of a conceptual analysis presented by Jarkko Kari [10], information can be generally formulated as a

*Address correspondence to this author at the Department of Information Studies and Interactive Media, 33014 University of Tampere, Finland; Tel: +358 $400614676 \quad$ (GSM); Fax: +358 3 3551 6560; E-mail: jarkko.kari@uta.fi meaningful representation which depicts some part of the perceived reality, and is outside a person's mind. The content of a speech, a book, or a Web page are a few typical examples of information.

On the other hand, outcomes have been named "outcomes" (e.g. [2]), "consequences" (e.g. [8]), "results" (e.g. [6]), "products" [5] and "impacts" [4]. Such words easily sound a static note, as if the information process terminated in some kind of an end state. Anders Hektor warns us against such a notion:

If it is acknowledged that information-activities are in a constant process of resolution, as part of an on-going making of reality, it is alien to that process to stop and say, "Here's the result!" Any arbitrary point in time will suggest products of an information-activity that in the next instance has changed "in a continuous and always incomplete process of becoming" [5, p. 93].

It would indeed be prudent to assume that outcomes are processes rather than 'things'. Therefore, I define outcome of information as any process that ensues from receiving a message - whether it happens intentionally or not (cf. e.g. [2]). This definition rules out those consequences of information which do not come about through an actor (e.g. person or community). Information coming true (on its own), for instance, is not an outcome of information in the sense meant in the current article. To qualify, then, there has to occur some kind of informing or being informed which then enables or gives rise to an outcome. It is as if the information is more or less converted into something different by the actor.

The study at hand is set in the spiritual domain, because this is an anomalous context which has rarely figured in information science research [11]. It analyzes the outcomes of 
spiritual information via publications containing such information. This paper cannot be framed as a study of the goals or objectives the authors of these documents hope to achieve, because the analysis also looks at the real, non-existent and conditional outcomes of any spiritual information (not merely of the documents themselves) - as perceived by the sources. The idea is just to get a very basic understanding of how the originators view the outcomes of such information. After this first step has been taken, subsequent studies can then investigate into the 'real' outcomes of spiritual information by ascertaining how it is interpreted and applied by endusers, for example.

Spiritual information (SI) may be about the spiritual or something else, but its defining feature is that it is perceived as a message originally provided or received by extraphysical means (cf. ibid.). In other words, the information is reportedly provided through a method not based on physical matter or energy, or received through a method other than the normal five senses. Plenty of examples illustrating the concrete nature of SI will be given in sections 2.2 and 4 . In different branches of the human sciences, some studies (e.g. [12-15]) have been conducted on what roles certain types of spiritual information play. These investigations have not directly focussed on the outcomes of information, however. There has also been a heavy emphasis on information allegedly received from spirits, at the cost of other sorts of spiritual information.

On the map of information science, the study at hand is primarily associated with the area of information use research. The outcomes of information include much more than just information use, however. Thus, by increasing our understanding of information outcomes, this investigation fosters broadening the scope of research looking at what happens after information seeking.

\section{LITERATURE REVIEW}

This section surveys all known scientific studies dealing with more than one sort of outcome of information phenomena. The information facet in the 'equation' was interpreted quite liberally (see the second paragraph in the previous section) in order to attain sufficient variation in the outcome facet. Hence, literature treating of the outcomes of, say, information seeking [7] - and not just information - was accepted, as well. The studies examining a single type of outcome were excluded, because there would have been too many publications to review. On these grounds, much literature - like Kari's [16] research on using spiritual information - was left out. The first subsection reviews outcomes of information in general, and is arranged by the aspect of the outcomes. The second subsection reviews outcomes of spiritual information, and is arranged by the type of spiritual information.

\subsection{Outcomes of Information}

The research literature has identified certain types of outcomes. Judith Larsen [17-18], for example, proposes that information can be modified (changed, adapted, reinvented) or used (implemented). Kari interviewed 16 Finnish paranormalists about their information needs, seeking and outcomes related to the paranormal. The outcomes of informa- tion consisted of information use and effects of information, which were categorized and calculated in considerable detail. [19] That doctoral dissertation includes an analysis of information outcomes that is more circumstantial than in any other study to date. The author continued his research in a conceptual paper, presenting a more extensive typology of the outcomes of information. The main classes remain the same, but it is stressed that using information requires active involvement by the person, while an effect of information is passively received by the person. [2] This work was subsequently picked up by Sabah Al-Fedaghi [20], who further elaborated on the concepts of information use and effect. McCreadie and Rice [1] frame the outcomes of information seeking as retrieving and actually using or consuming information, evaluating the information, as well as possibly redefining and reiterating the process. In Brenda Dervin's [21] Sense-Making methodology, outcomes are seen as helps versus hindrances; functions versus dysfunctions; consequences and impacts; as well as future horizons. The axis of positivity is characteristic of this approach, for it is assumed the fodder that sense-makers use may lead to useful, hurtful or non-useful outcomes [22, p. 739].

In order to catch a more concrete glimpse of information outcomes, let us look at some examples. These are provided by Gloria Leckie and Karen Pettigrew, among others:

The optimal outcome is that the information need is met and the professional accomplishes the task at hand, such as diagnosing an ailment, or completing a technical report. Some of the common outcomes of information seeking identified in the literature include: providing a service or product, completing paperwork, realizing operational goals, and achieving professional development goals. It is possible, however that the outcome of the information seeking is that the need is not satisfied and further information seeking is required [7, p. 103].

David Nicholas, Paul Huntington and Peter Williams note how policy initiatives presume that the provision of information to people in itself leads to better health outcomes. They criticize such simplistic thinking by bringing out potential improvements in the discussion between health professional and patient, which could then lead into better treatment [23].

A number of different dimensions have also been detected in the outcomes of information. One is manifest consequences (intended and recognized changes) versus latent consequences (unintended and unrecognized changes) [17]. Hektor's research reveals that when people interact with messages, its outcomes can be cognitive (thoughts), emotional (feelings), or behavioral (actions). Furthermore, he distinguishes the facet of transience or durability:

For instance, not all information-activities should be expected to necessarily result in lasting but hidden products. A few hours in front of the television, or browsing the web, or visiting the movies may provide nothing more lasting than a temporary feeling of release and relaxation [5, p. 94].

In addition to the activity of information outcomes (active versus passive; see above), Kari detects four other dimensions: 
- actuality - whether the outcomes are potential or real

- immediacy - whether the outcomes are immediate or delayed

- physicality - whether the outcomes are physical or mental

- number - how many outcomes occur [2].

Finally, there has been some discourse on the dynamics of information outcomes, or how they work as a process or phase. It has been stressed that information may have multiple and even contradictory outcomes $[17,22]$. This is supported by Kari's empirical study which indicates that among the five phases of information action, the outcomes of information were most given to iteration. This means that the same information could have several uses and/or effects at different moments in time. [19] On the other hand, Dervin [22] finds fault with information seeking research having a habit of reducing the outcomes of many occurrences of sense-making to a single eventual outcome. This does not signify that such coalescence does not actually happen. Indeed, Kari [19] found that two information seeking processes or their subprocesses sometimes ended in a joint outcome. We must realize, however, that an outcome of information is not an inevitable consequence of information seeking (see [24]). Ragnar Audunson [25] calls these incidents in which information is not utilized or is worthless "anomalies". In Kari's investigation, nobody answered that they did nothing with the information they had acquired (non-use was not, however, directly asked about from the participants). As to valueless information, there were a few cases in which the knowledge was utilized, but without avail. [19] Other data might well contain cases where information does not entail any perceptible outcome.

In the absence of pertinent research, one may presume that different varieties of information lead to different outcomes [26]. It has also been concluded that if information need is a question, then information outcome signifies how the obtained answer is put to work by people and aids them in reaching their goal [19].

\subsection{Outcomes of Spiritual Information}

One type of spiritual information is holy writings. By interviewing one priest in the United States of America, Daniel Roland conducted a case study on his interpretation of Scripture for preparing the weekly sermon. The participant tried to be faithful to the Word, and the utility of the Bible was obvious: "The informant articulated the need to let the Word of God speak to him early in the sermon preparation process as a way to determine the direction, focus, and goals of the sermon" (p. 116) [27].

Dreams are often considered as a type of SI. In an article by Athena Drewes, some of Louisa Rhine's (an American parapsychologist) research data (posted letters) are examined. Rhine reportedly analysed 433 cases of precognition (knowing future events beforehand) in which the persons had taken an ESP (extrasensory perception) experience (a dream) of theirs seriously, and tried to head off its occurrence. Rhine "also found nine precognitive cases in which the percipient would have been directly involved in some tragedy had he or she not taken some action because of his or her precognitive dream". [28, p. 360] In an ethnographic investigation, the magical practices of native Amazonians are scrutinized by anthropologist Michael Brown. The roles of dream visions are discussed at one point. The Aguaruna people considered visionary knowledge as a vital instrument for building their own identity, and for developing means by which their self can impact and manipulate the surrounding world. "Killing visions" were considered as important at a time when the tribe was still engaged in wars, for they were treated as distant causes that make it possible to succeed in battle. According to the research, "Life-giving [...] visions have a similar role with respect to domestic accomplishments". Moreover, it was thought that a vision-seeker's images about the future replace uncertainty with order [29, pp. 166-167].

A theoretical article by J.-M. Decuypere deals with the nature of channeling which is defined as communication with beings who supposedly inhabit a level of reality 'higher' than ours (the physical one). The sole thing which the author has to say about information use is this: "When channelling deals with the medical or psychological problems of individuals needing help, the utility of the information given is immediate and can be evaluated regardless of the source" (p. 199). The sources of channeled information claim to foster human evolution [30].

Channeling is at the heart of Diana Tumminia's in-depth ethnographic investigation focusing on prophecies in an American UFO group called Unarius. The study found that channeled information - mostly from Space Brothers shaped the bulk of the history of the organization, adapting it and twisting it in many ways. Archangel Uriel's supposed words, conveyed by two intermediaries, were able to guide the community. The emerging channelings constructed the leadership type as well as emotional norms which the group would adopt. In line with a belief in reincarnation, memories of their past lives had also been awakened among the members, spurring a higher level of resolve: "Once they started to realize collectively what had happened in their past lives, they prepared themselves to deal with the "ego" problems of succession" (i.e. who would be the next leader of the community; p. 135). However, it was messages channeled by some students in the group which led to a cooperative and egalitarian succession period. The board of the association sought the Space Brothers' advice, so their activities would be grounded on a higher authority. They legitimated the new organizational structure via improvised channeling. The author also notes that excitement built when a predicted date of UFOs landing neared in 2001. However, the spaceships did not show up [31].

Mediumism is a concept very close to channeling. The difference seems to be that mediumistic communications reportedly originate from dead persons rather than 'higher' spirits or extraterrestrials. Didier Bertrand [12] studied the therapeutic role which Khmer mediums play in Cambodia by interviewing 23 mediums, some 60 disciples of theirs, and 105 patients, as well as by observing ceremonies and rituals. He found, among other things, that "Cambodians who consult mediums believe that disease and misfortune are undesirable disorders which are the expression of supernatural forces that cause illness and misfortune and that they can be resolved through divination" (p. 320). Through the mediums, 
it appears, spirits tell patients what ails them and suggest a remedy or ritual that should be performed. It is significant that the mediums provide access to knowledge that enables the sufferers to take care of their problems accordingly. According to the data, people "rarely go to the nearest medium to speak about their intimate problems, however, since the consultations are given in public, and they are reluctant to have their private affairs made known to their community" (p. 317). It was also discovered that the effect of treating patients with medicines could be strengthened if the medium simultaneously uttered prayers or magic incantations, or if borameï (spirits serving Buddhism) were sensed to prescribe the medicaments. These spirits appeared to act through mediums to encourage righteous behavior in their patients. In every case,

The answers provided by the borameï relieve the anxiety caused by confrontation with the unknown, and external dangers beyond the patient's control. Through a hypertrophy of the self, the patient being told to be better and stronger finds stability and power and leaves strengthened from their encounter(s) with the medium [12, p. 325].

Mediumistic communication has also been investigated among 'modern' Westerners. Fieldwork - consisting of participant observation at six events and interviews with seven counsellors in England - was carried out by Tony Walter [15] in an effort to explore what the meaning of visiting mediums is to mourners. As a general introduction, Walter remarks how similar mediumistic messages are in contemporary spiritualism. The core content typically includes certain phrases by which the intermediary or source (a departed soul) apparently wants to influence the recipient: "don't shed any tears", or "you can get on with life without worrying about him/her" (p. 95). The mediums' messages promote a calm manner of moving on, but with the dead still being a part of one's life. Mourners who visit a medium for the first time may respond to the received message in various ways:

They may accept the medium's authority; or they may not; or they may remain agnostic. They are impressed, or they are not, or they are not sure [15, p. 96].

If the customers are impressed, the reason is that they feel it would not have been possible for the medium to glean the knowledge by 'reading' the customer. It does seem the clients' most common reaction was uncertainty. Nevertheless, consulting mediums was mostly seen as beneficial, and there was only one case in which a 'reading' by a medium disturbed the person. However, some customers worried about what their priest or counsellor would think about their visits to a medium, and so they kept it secret [15].

Finally, some research has been published about people's experiences of being directly informed (i.e. without an intermediary) by spiritual beings. Damaris Drewry's [14] interview study with seven participants from the USA focuses on the role of after-death communication (ADC) in bereaved individuals' recovery. She defines ADC as a directly and "spontaneously experienced contact with a deceased loved one" (p. 74). The therapeutic gains identified in earlier literature include:
- To provide comfort and reassurance that love continues on after death

- To assist the death transition: deceased loved ones return to help the dying

- To give advice and solve problems

- To protect by giving warnings of impending accidents to be avoided

- To show meaning in life and death

- To confirm hope that there is life after death

- To provide a new sense of life purpose for the mourner

- To establish a new relationship with the deceased by completing unfinished business. ADC can reduce the anger, guilt, anxiety, and depression associated with the death of a loved one, thereby assisting the survivor to move forward

- To demonstrate that the loved one has not abandoned the survivor

- To provide information not previously known but needed by the bereaved [14, p. 77].

Some of Drewry's results verified previous findings, but most seemed to be new discoveries. The ADCs were usually unexpected, and this established their authenticity for the bereaved individuals. The paper reports that ADC apparently influences the survivors in many ways. Even if the informants were initially frightened, every ADC was described as eventually beneficial. The partakers said experiencing ADCs made them feel privileged and blessed. "To varying degrees, they reported an expanded awareness of the meaning of life and death, feared death less, felt confirmed in who they believe themselves to be, and had a new understanding of themselves in relation to a bigger picture or universal grand plan" (p. 78). The bereaved proclaimed "immediate relief, comfort, hope, love, emotional stabilization, encouragement, forgiveness, and the joy of continuing relationship" (p. 79) after ADC. Owing to their ADCs, all interviewees observed having been able to start, continue or complete their grieving process. Only one of the reported 40 ADCs resulted in the percipient's complete liberation from grief, though. ADC also assisted the bereaved in bringing unfinished business to a conclusion with the deceased. One more common outcome of ADCs was that the interviewees reframed their relationship with themselves, the deceased, and the divine. A major conclusion of the study is that the higher risk of people dying of bereavement could be considerably reduced if society promoted after-death communication [14].

An inquiry concerning prayer was conducted by Simon Dein and Roland Littlewood [13] by means of surveying and interviewing 40 Pentecostalists in England. The article focuses on their perceptions of extrasensory voices they hear. Sometimes the participants were told verses which they claimed not to be familiar with. When they looked them up in the Bible, they found that what they had heard coincided with the scripture. A pastor among the informants regarded the voices with some reservation. For him, the voices originated from a divine source only when a person's behavior changed in a morally significant way after being informed by 
Table 1. Theory and Practice of Qualitative Data Analysis

\begin{tabular}{|c|c|}
\hline Analytic Moves in Theory [32, p. 9] & Analytic Moves in Practice (This Study) \\
\hline Affixing codes to a set of field notes drawn from observations or interviews & The text extracts drawn from the spiritual publications were coded \\
\hline Noting reflections or other remarks in the margins & $\begin{array}{l}\text { Certain points to remember were noted in a memo and the article manu- } \\
\text { script-in-progress }\end{array}$ \\
\hline $\begin{array}{l}\text { Sorting and sifting through these materials to identify similar phrases, rela- } \\
\text { tionships between variables, patterns, themes, distinct differences between } \\
\text { subgroups, and common sequences }\end{array}$ & $\begin{array}{l}\text { Those materials were sifted through in order to find similar expressions and } \\
\text { themes, as well as commonalities, differences and relationships between the } \\
\text { categories of information outcome }\end{array}$ \\
\hline $\begin{array}{l}\text { Isolating these patterns and processes, commonalities and differences, and } \\
\text { taking them out to the field in the next wave of data collection }\end{array}$ & $\begin{array}{l}\text { After each class had been identified, it was tested against more data in the } \\
\text { corpus, so that it could be changed, specified, merged with another class, or } \\
\text { even deleted }\end{array}$ \\
\hline $\begin{array}{l}\text { Gradually elaborating a small set of generalizations that cover the consis- } \\
\text { tencies discerned in the database }\end{array}$ & The main categories (types of outcome) were developed \\
\hline $\begin{array}{l}\text { Confronting those generalizations with a formalized body of knowledge in } \\
\text { the form of constructs or theories }\end{array}$ & $\begin{array}{l}\text { The outcomes of spiritual information were compared with those examined } \\
\text { in earlier research (see section 5) }\end{array}$ \\
\hline
\end{tabular}

such speech. If this did not happen, it was improbable that he/she had heard God's voice. Nevertheless, most participants perceived the voice of God answering to their prayers, but their reaction to His behest was ambiguous:

Although generally our informants state that they would automatically obey God's voice, in practice many tell us that they have not: they still have a degree of freedom. They feel themselves clearly responsible for whether they do obey [13, p. 224].

The authors observe that this feature of choice distinguishes the voice of God from pushy voices experienced in a state of mental illness. Many of the informants reported the utility of God's voice in doubtful or difficult situations [13].

\section{MATERIALS AND METHODOLOGY}

The empirical material for this study comprised of spiritual information. To be more specific, Finnish publications reportedly produced by means of a spiritual method were sought out. The search was fairly extensive, covering the most relevant general databases and spiritual forums. As a result, 109 promising documents ranging from the 1940s to the 2000s were obtained and processed (those which are cited in this article are listed in the References section). The processing involved scanning the pertinent parts (beginnings, endings, and sections dealing with information phenomena) of print publications (books and articles) into electronic format, so that they could be easily incorporated into a database for coding. The data also included ready electronic documents (Web pages and e-mail messages). As a whole, I would estimate that the corpus represents Finnish spiritual information made public very well, for it is unlikely that anything essential was left out.

In terms of methodology, interpretivism was chosen as the qualitative approach to data analysis. According to Mat- thew Miles and Michael Huberman, interpretivism is suited for studying both actions and 'texts' (whether oral or written). It entails the interpretation of meanings, and particularly from the phenomenological point of view, aspires to do this by "'deep understanding', an empathy or indwelling with the subject of one's inquiries" (p. 8). Interpretivists insist that investigators cannot be objective in their research, but may be just as entangled in their preconceptions as the sources of their data. This is because scholars, too, are members of certain (sub)cultures at a particular historical moment. Often their research work is affected in unnoticeable ways [32]. I myself have been monitoring the spiritual scene in Finland for almost three decades now. Claiming to know and comprehend the field rather well, I would not say that an outsider bias is a risk factor here. My training and scholarship as an information scientist naturally guide me to conceptualize the research object from the perspective of information, but I would think of this as providing focus, rather than something distorting the analysis. And yet, no matter how high-quality examination I aimed at, we must realize that the findings of this investigation reflect my own interpretations.

Miles and Huberman [32] also present general guidelines for the process of qualitative data analysis, which are enumerated in Table 1. On the right-hand side, this table shows how the study at hand followed the principles. The empirical work was quite faithful to the guidelines, except that all data were collected before the analysis began. In retrospect, the amount of textual material was about right, because theoretical saturation was reached, but not until towards the end of the analysis. All relevant outcomes of information could be classified - at least at the most general level - so the data were quite unambiguous. Moreover, the empirical categories arose 'naturally' from the data, without much struggle. The most challenging part was to construct typologies in which 
Table 2. Categories of Processing Spiritual Information

\begin{tabular}{|c|c|c|}
\hline Category & Variations & Example \\
\hline Handling & holding, preserving & $\begin{array}{l}\text { "So our thanks to all parties, who process our } \\
\text { book in such a way that our words do not get } \\
\text { muddled nor our feelings disappear, which } \\
\text { we've invested in our book" [39, p. 466]. }\end{array}$ \\
\hline Examining & $\begin{array}{l}\text { examining, searching for something, checking, } \\
\text { comparing, analyzing, going through }\end{array}$ & $\begin{array}{l}\text { "The values given by me come from the Infor- } \\
\text { mation Field of the Universe, and they cannot be } \\
\text { directly compared with numbers, as you have } \\
\text { sometimes done" [41, p. 26]. }\end{array}$ \\
\hline Internalizing & $\begin{array}{l}\text { 'cracking a nut', digesting, attaching to one's prior } \\
\text { knowledge, taking into one's heart }\end{array}$ & $\begin{array}{l}\text { "It is decisive how the given, new teaching can } \\
\text { be attached to earlier, understood compendiums } \\
\text { of awareness" [42, p. 216]. }\end{array}$ \\
\hline Thinking about & thinking, pondering, contemplating, associating & $\begin{array}{l}\text { "To them we communicate books for ponder- } \\
\text { ing" }[34, \text { p. 21]. }\end{array}$ \\
\hline Commenting on & $\begin{array}{l}\text { mocking, discussing, debating, criticizing, calling } \\
\text { source names, sullying }\end{array}$ & $\begin{array}{l}\text { "Often people who see visions have been called } \\
\text { goofy" }[43, \text { p. 150]. }\end{array}$ \\
\hline Transforming & $\begin{array}{l}\text { changing, clarifying, distorting, correcting, affect- } \\
\text { ing, translating, formulating, standardizing, com- } \\
\text { bining }\end{array}$ & $\begin{array}{l}\text { "Likewise we wish to give thanks to all those } \\
\text { parties, who will process our book so as to ren- } \\
\text { der it legible" }[39, \text { p. } 465] \text {. }\end{array}$ \\
\hline Eliminating & erasing, voiding, forgetting & $\begin{array}{l}\text { "Now has come a new age, has come new in- } \\
\text { formation to you, which been forgotten, put } \\
\text { aside as fables" [33, p. 9]. }\end{array}$ \\
\hline
\end{tabular}

the classes make sense in relation to each other. The distinctions were sometimes subtle, but not impossible to make. For almost every subcategory, more than one empirical instance could be found, so through this richness of material, the typologies gained validity.

\section{RESULTS}

\subsection{General Outcomes}

Sometimes, the outcomes of spiritual information were expressed in fairly indefinite terms, so that the type of outcome was impossible to determine. One of the sources said, for instance, that a particular sacred book contains information and advice for everything [33]. This was by far the most comprehensive outcome statement. In another case, there were distinct outcomes, but they were unnamed. The text [34] just mentioned predictive warnings about what kinds of outcomes may ensue, if humanity does not follow the laws of the universe. Such laws were presented as SI. In a third publication [35], it was written that the spiritual information given has a certain purpose - without specifying it. A purpose like this obviously signifies that the source of the information intended it to have a particular outcome. Several of the writings contained a reference to whether SI is provided in vain. Most of them stated that SI is not given in vain, as exemplified by the quote "We do not tell you this in vain, for we know your destiny in everything" [36, p. 10]. One source [37] expressed the concept in terms of spiritual infomation not going to waste. These affirmations suggest that SI is consequential. There was only a single instance of SI transmitted in vain: if such information is provided in a form which surpasses the recipient's understanding, it is futile information [38].

Evidently, those findings imply that spiritual information usually has outcomes. The various types of outcomes are analyzed in the rest of the results section, each under its own subheading.

\subsection{Processing Information}

Processing information meant doing something to spiritual information - whether this 'doing' happened outside or inside an actor. Once, the processing activity was expressed very vaguely: a book had been processed in one way or another [39]. A little more detail was divulged when another source stated that a booklet needs not be treated with emotion [40]. This was just about the only clear instance of affective information processing; the rest were predominantly cognitive. Each of the seven categories in Table 2 represents a particular facet or phase of processing SI.

\subsection{Dispositions to Information}

Disposition to spiritual information was another outcome. This theme was about what views the recipients take of the information or how they feel about the information after acquiring it. As Table $\mathbf{3}$ shows, the dispositions could be quite simply classified as positive, neutral or negative. Neutral views were not as numerous as the others, so the dispositions were dominated by opposites. This was also directly expressed in the data. For example, we may either reject or accept what the Universe announces [44]. SI evoked contradictory reactions, too. According to a book written by Ritva Fagerström, many people experienced her previous book 
Table 3. Categories of Disposition to Spiritual Information

\begin{tabular}{|c|c|c|}
\hline Category & Variations & Example \\
\hline Positive & $\begin{array}{l}\text { being positively disposed, considering as truth, } \\
\text { trusting, feeling joy, feeling zeal, experiencing } \\
\text { interest, judging important, respecting, admiring, } \\
\text { believing, regarding as publishable, being pleased, } \\
\text { being grateful }\end{array}$ & "Once again, I stay lower [in the spiritual world] to digest an \\
\hline Negative & $\begin{array}{l}\text { experiencing difficulty, taking SI hard, regarding as } \\
\text { gloomy, being disappointed, feeling unpleasant, } \\
\text { objecting, fearing, reckoning as non-spiritual, con- } \\
\text { demning, considering as fiction, doubting, being } \\
\text { critical, not believing }\end{array}$ & $\begin{array}{l}\text { After we die, "we are to see our life on earth and now under- } \\
\text { stand it in another way. [...] In consequence, it is difficult for us } \\
\text { to see all that, what evil in our life we've done and how we've } \\
\text { brought unhappiness to others. [...] Tough is that sight for } \\
\text { many, great is then one's distress due to everything seen, and } \\
\text { miserable is the human who has done a lot of evil, sorrowful is } \\
\text { the view which (s)he gets to watch. [...] A gloomy sight is it to } \\
\text { us humans and a great disappointment to many, for it leaves } \\
\text { nothing unshown, but we get to see the truth in all its naked- } \\
\text { ness." [46, p. 9] }\end{array}$ \\
\hline
\end{tabular}

from high spirits as interesting, but difficult to believe. They wanted to believe in it, but their reason objected [34]. Contrary to processing SI (see section above), the dispositions to SI seemed much more emotional.

\subsection{Communicating Information}

Spiritual information was also communicated (or not communicated) onwards in various ways, as shown by Table 4. No doubt, many of the communication categories seem mutually inclusive. Some explanation is therefore in order. Transmitting refers to instances in which supernormal beings (usually spirits or extraterrestrials) alleged to relay information from 'higher' sources to us. On the other hand, channeling means that certain normal beings (mostly humans) conveyed information from supernormal beings to us, trying to retain the original composition of the message. The "vibrating" and "transferring" variants of channeling were special in that the beings reported to be doing these things were whales. Paraphrasing was similar to channeling, except that the intermediaries expressed the message in their own words. Thus, the conveyed information was merely an approximation of the original information, not an exact replica of it. Sharing concentrated on the dissemination of SI. Usually, it was not performed by those who claim to obtain spiritual information first-hand (i.e. the intermediaries), but by people who obtain such information second-hand (i.e. from the intermediaries). Storing signifies that SI was transferred to another carrier of information, but not communicated to other beings. Hiding was actually the opposite of communicating, for the actor deliberately withheld information from others. Although these last two categories do not reflect the communication of information per se, they are useful constructs as communication 'anomalies'. Taken together, communicating information exhibited a social perspective on the outcomes of information.

\subsection{Using Information}

Information use signified doing something with spiritual information. Sometimes, the nature of use was not specified at all: the sources just mentioned the possibility of using information in the so-called Akhasia Book, the truths contained in the Book of Life being disposable, and information on crystal energy having been used. One publication [34] revealed a little more detail by saying that people can use a spiritual name in their mind. In another text [50], it was proclaimed that God's information has to be used right. These were just isolated cases, however. The great majority of the observations could be classified as a distinct type of information use; these are outlined in Table 5. First of all, introducing does not tell us so much about the kind activity as the stage of the process: when spiritual information was introduced, it means that the actors began using it.

The terms "exploiting", "utilizing" and "implementing" have similar connotations, and hence these categories may be easily mixed up. Exploiting SI happened when the actors consumed information by incorporating it into themselves; the "drawing from" variant describes the essence of this process well. On the other hand, utilizing spiritual information involved wielding information as an instrument in some activity. One book [55], for instance, stated that a piece of advice given in it can be used to acquire the skill of thought transference (telepathy). The utilization of information exhibited considerably more variation than the other types of information use - probably reflecting the fact that utilization was a more concrete type than the others. Then again, implementing could be defined as putting SI into practice. It was like the information had a latent manifestation in reality. Then it was chiefly a matter of 'translating' the information into action, and thus making the information come true. The subcategory of "not offending" originates from a source who stressed the importance of not breaking spiritual laws [53]. 
Table 4. Categories of Communicating Spiritual Information

\begin{tabular}{|c|c|c|}
\hline Category & Variations & Example \\
\hline Transmitting* & $\begin{array}{l}\text { transmitting, intermediating, singing, telling, giving, } \\
\text { bringing forwarding, speaking, taking }\end{array}$ & $\begin{array}{l}\text { "This spirit plane too may be solely a transmitter of infor- } \\
\text { mation coming from on high, and there can be even several } \\
\text { of these transmitters depending on the receiving physical } \\
\text { person's developmental level and potentials" [35, p. 107]. }\end{array}$ \\
\hline Channeling* & $\begin{array}{l}\text { channeling, conveying, expressing, dealing out, } \\
\text { writing as messages, speaking as messages, painting } \\
\text { as art, drawing as pictures, playing as music, mani- } \\
\text { festing as creativity, vibrating*, transferring* }\end{array}$ & $\begin{array}{l}\text { "It would not have been possible for us to get this book } \\
\text { within your reach without our channeler, but it would have } \\
\text { been even more impossible for her to make this book with- } \\
\text { out the words which we gave her for writing down" [47, p. } \\
\text { 179]. }\end{array}$ \\
\hline Paraphrasing* & saying, telling about, advancing an interpretation & $\begin{array}{l}\text { "Now I'll tell about the experience which I've just myself } \\
\text { had and so you can tell others about it, who come to you } \\
\text { and are in need of such help as I myself was in my time" } \\
{[48, \text { p. 8]. }}\end{array}$ \\
\hline Sharing* & $\begin{array}{l}\text { sharing, forwarding, declaring, presenting, showing, } \\
\text { bringing, publishing, disseminating }\end{array}$ & $\begin{array}{l}\text { "From priestesses to oracles, from clairvoyants to fortune- } \\
\text { tellers there have been people who have had more knowl- } \\
\text { edge than others. But earlier their information only spread } \\
\text { locally, and like gossips it was prone to transform on its } \\
\text { way. Only printing gave the opportunity to spread the truth } \\
\text { word for word in its original form on a larger scale. [...] } \\
\text { Now the majority of the whole humankind can be reached } \\
\text { with the help of the printed word." [34, p. } 21]\end{array}$ \\
\hline Storing* & $\begin{array}{l}\text { writing down, documenting, copying, lodging in } \\
\text { heart, aggregating }\end{array}$ & $\begin{array}{l}\text { "write down what tells your heart of hearts, your expanding } \\
\text { consciousness" [33, p. 27] }\end{array}$ \\
\hline Hiding* & hiding, keeping secret, not releasing & $\begin{array}{l}\text { "Therefore the Catholic Church does not want to release all } \\
\text { information. However, the truth is that they do not belong to } \\
\text { one Church and to be kept secret, but they belong to teach- } \\
\text { ing to all of humankind." }[49, \text { p. } 58]\end{array}$ \\
\hline
\end{tabular}

*These are clarified in the body text.

We may reason that if intelligent beings do not offend SI, they are likely to adhere to it. All in all, information use could be best characterized as a functional outcome of information.

\subsection{Effects of Information}

Finally, it was reported that spiritual information may have a multitude of effects. That is, the information can change various - most frequently human - phenomena. It was, again, not always quite clear what sorts of impacts the originators of the information meant. Spirits strived to influence with books, an energy picture had effects, and a story could be beneficial, but these instances did not name what is affected. Fortunately, nearly all effects of SI were presented in more detail. The majority of these were most naturally classified by their directness - from enabling to direct effects (see Table 6). The class of enabling contains the most indirect impacts: spiritual information either made something possible, or was a prerequisite for something. Typically, information in the activating category 'activated' people to do something. The effects included a few anomalous variants, however - namely people quiet, do not want, do not hate, and do not resent. In these cases, SI actually worked in the opposite way by 'passivizing' people, or stopping them from doing something.
The direct effects of information were the most intense. It was almost like spiritual information was a force or entity arranging some part of reality (also the metaphor of dictating comes to mind here), without any intervening factors or human involvement (other than as targets of the impacts). Lastly, the category of harmful effects cannot be positioned on the continuum of directness, because it contains effects which would otherwise be classified under the other five main categories. While the "enabling", "supportive", "steering", "activating" and "direct" influences of information were depicted as positive or neutral events, the type "harmful" collects all the negative influences under one rubric. The effect depriving of gift status may sound cryptic. It was written that angels wanted to give each member of the audience a spiritual gift, but they could not tell them what it was, because then it would not be a Christmas present [58]. Among the harmful effects of SI, this was the least harmful one. Overall, the effects of spiritual information may be best described as autonomous outcomes of information: humans (and other beings) appeared to have more or less limited control over how the information shapes the world.

\section{DISCUSSION}

This study perused a body of spiritual texts, and discovered five types of information outcome: processing, disposi- 
Table 5. Categories of Using Spiritual Information

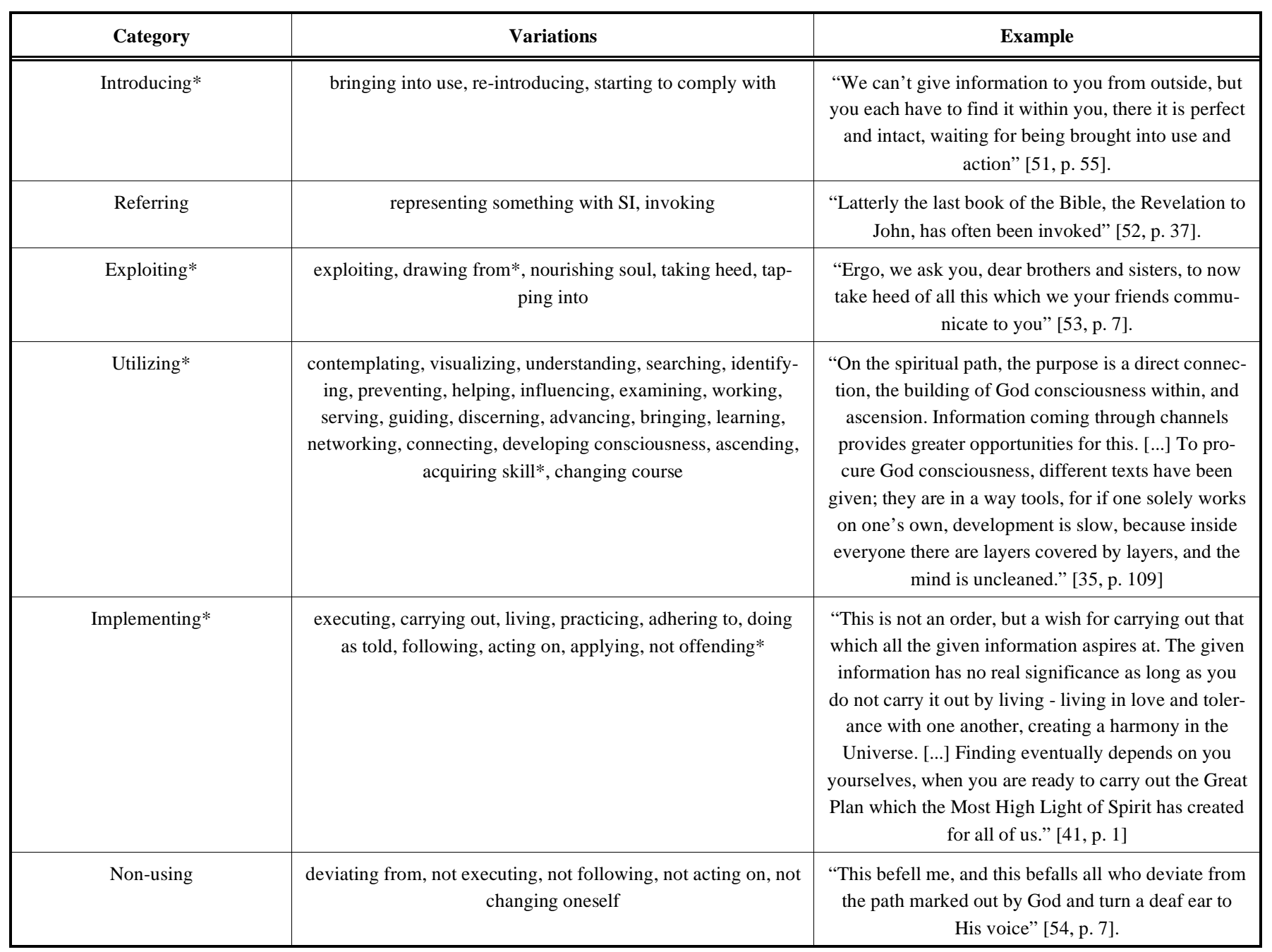

*These are clarified in the body text.

tions to, communicating, using, and effects of information (see Fig. 1 below). There were also general outcomes of information, but they do not count as a type of outcome. All five kinds of outcome have been researched before, at least to some extent, but it has been quite rare to examine even two kinds of outcome in one study. Here is how the outcomes found in previous research seem to map onto those found in the current investigation:

- Modifying and using information [17-18] are about the same as processing and using information (this study).

- Uses and effects of information [2, 19-20] are the same as using and effects of information (this study).

- Retrieving, using and evaluating information, as well as redefining information seeking [1] only have counterparts in using and processing information (this study), so the first and last activities (retrieving \& redefining) are not really covered by the newfound outcomes. Then again, one may claim that information seeking is primarily a process which precedes the outcomes of information, and is only in a secondary sense an outcome of information.

The five outcome types were also characterized with the adjectives cognitive (processing information), affective (dispositions to information), social (communicating information), functional (using information), and autonomous (effects of information). As we saw in section 2.1, Hektor [5] distinguishes between cognitive (= cognitive in this study), emotional (= affective) and behavioral (mostly functional) outcomes, and Kari (e.g. [2]) distinguishes between mental (mostly cognitive + affective) and physical (mostly functional) outcomes.

These comparisons demonstrate that some of the major categories (e.g. dispositions to \& communicating information) have not been studied together before, at least as outcomes of information. On the other hand, the present research did not find information seeking to be an outcome of information, albeit the result could have been different with some other data, perhaps in another context. The five types of outcome were also categorized at a general (the rightmost boxes in Fig. 1) and specific level (Variations in Tables 2-6), 
Table 6. Categories of Effect of Spiritual Information

\begin{tabular}{|c|c|c|}
\hline Category & Variations & Example \\
\hline Enabling* & $\begin{array}{l}\text { people complete, are able, learn } \\
\text { to do things, maybe do not have } \\
\text { to do things, attain, find } \\
\text { opportunities; something } \\
\text { becomes understandable }\end{array}$ & $\begin{array}{l}\text { "When you listen to me with ears well hearing, with minds } \\
\text { open to a lesson, perhaps you will not need to experience it all, } \\
\text { to undergo every test, which I in my time had to there roam due } \\
\text { to selfish nature, human's smugness" [45, p. 4]. }\end{array}$ \\
\hline Supportive & $\begin{array}{l}\text { supporting, strengthening, } \\
\text { facilitating, encouraging, helping, } \\
\text { relieving, increasing, advancing, } \\
\text { improving comprehension; things } \\
\text { become clear; people get zest to } \\
\text { do something, get answers, find } \\
\text { something anew }\end{array}$ & $\begin{array}{l}\text { "Had Jesus' truth not been allowed to spread to all, you would } \\
\text { still be both spiritually and in the respect of your science as } \\
\text { well as culture at a considerably lower level than at present. } \\
\text { The same goes for the founders of other religions, that is, their } \\
\text { prophets, for they all have been born to bring you truth and so } \\
\text { to help your progress on the path of spiritual } \\
\text { development." [34, p. } 84]\end{array}$ \\
\hline Steering & $\begin{array}{l}\text { steering, guiding; } \\
\text { people work in specific way }\end{array}$ & $\begin{array}{c}\text { "It is so that the information of the universe steers events as it } \\
\text { has been ordained" [56, section "'Jumalattaren Syntymä' } \\
\text { maalaus"]. }\end{array}$ \\
\hline Activating* & $\begin{array}{l}\text { people react, decide, accede, } \\
\text { take stand, receive; people start } \\
\text { to love, inform, pray, sing, think, } \\
\text { illuminate (spiritually), search, } \\
\text { honor, humble themselves, do } \\
\text { something; people quiet*, do not } \\
\text { want*, do not hate*, do not } \\
\text { resent* }\end{array}$ & $\begin{array}{l}\text { "The most important significance of mediums who use } \\
\text { different instruments is in that the clients perhaps begin, owing } \\
\text { to the answers they got, to think about their own life and adopt } \\
\text { a new kind of attitude toward it" }[52, \text { p. } 76] \text {. }\end{array}$ \\
\hline Direct* & $\begin{array}{l}\text { protecting, consoling, opening } \\
\text { eyes (figuratively), changing } \\
\text { world view, provoking thoughts; } \\
\text { people feel safe, feel joyous, } \\
\text { understand, heal, remember, are } \\
\text { saved, are illuminated } \\
\text { (spiritually), do not become } \\
\text { confused; everything proceeds }\end{array}$ & $\begin{array}{l}\text { "These are the power incantations, with which the sick are } \\
\text { healed, also open memories of past lives" [33, p. 75]. }\end{array}$ \\
\hline Harmful* & $\begin{array}{l}\text { regressing, frightening, } \\
\text { petrifying (figuratively), } \\
\text { depriving of gift status*; people } \\
\text { get too much leeway, lose } \\
\text { possessions }\end{array}$ & $\begin{array}{l}\text { "You have traditionally interpreted books you've declared holy } \\
\text { in a very pernickety and formal way. This procedure has } \\
\text { petrified your life into the birth of limitations, a strict model, } \\
\text { which has prevented the possibility for changes typical of life, } \\
\text { rather than encouraged them." [57, p. 103] }\end{array}$ \\
\hline
\end{tabular}

*These are clarified in the body text.

yielding more detail about the concepts. To be sure, many of the categories have already been analyzed or at least mentioned in the research literature, but they are too numerous to be discussed here. The real contribution of this study is that it pulls together a multitude of various outcomes of information, and organizes them into a coherent, holistic typology. Such an effort has not been made previously on this scale. In so doing, the conceptual structure simultaneously implies that research areas which have earlier been considered as separate (e.g. information use and information sharing) can in actual fact be connected, if there is just a will to do it. The findings and conclusions are by no means limited to spiritual information. The typology is general enough to be applicable to information of various kinds, and hence it can be utilized when investigating the outcomes of information in other settings, too. It would be interesting to see to what extent the 


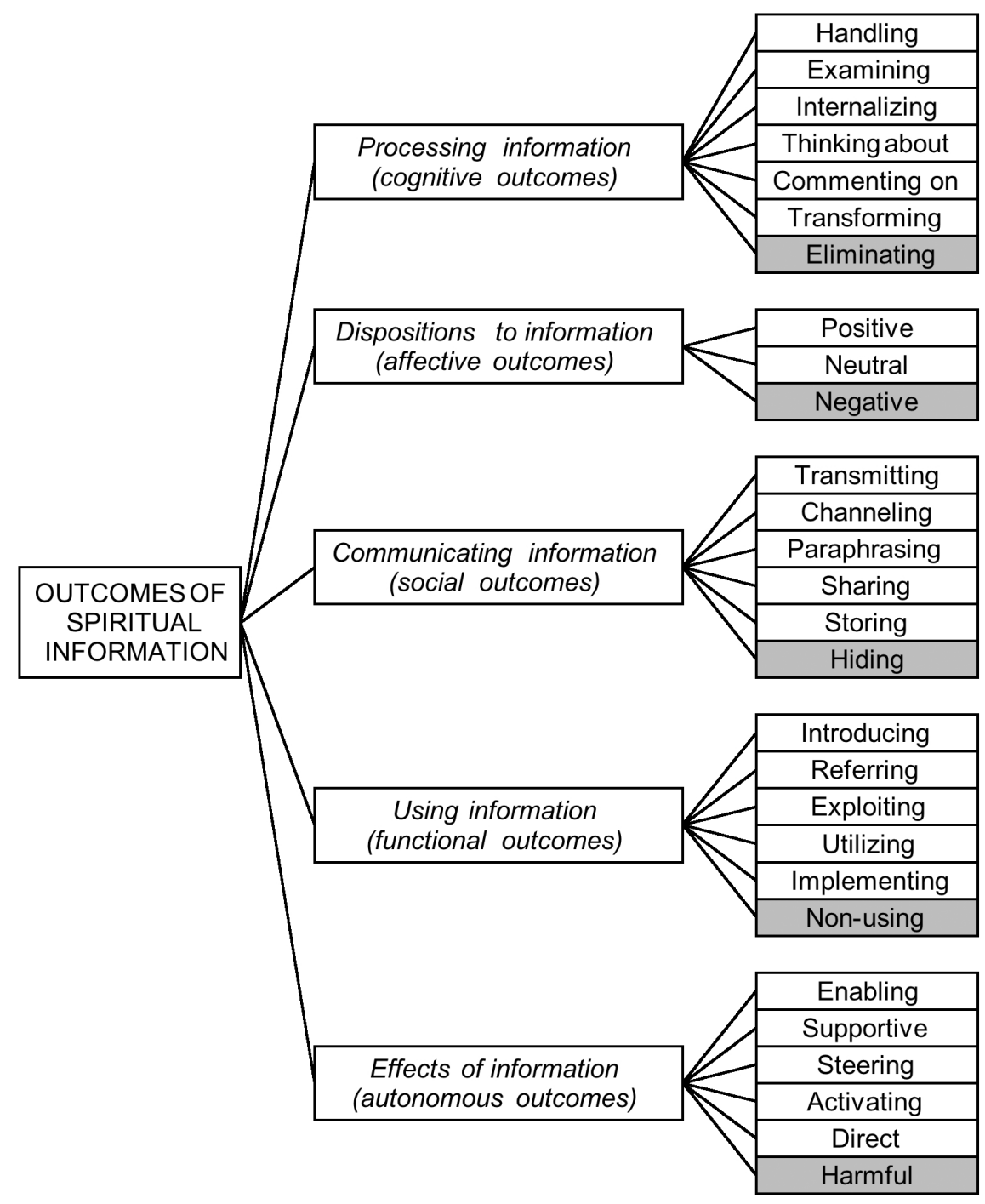

Fig. (1). A visual representation of the outcome categories.

identified categories of information outcome are applicable to other domains. It would be much more manageable, though, to concentrate on a single outcome type at a time, rather than include the whole framework. Of course, the more specific findings in this investigation are probably not so readily generalizable to other contexts, but this merely reflects another major contribution of the study: to describe how the sources of spiritual information perceive its outcomes. The data suggested that spiritual information is of great significance in all contexts, especially in everyday life, albeit there were also outcomes that can be regarded as trivial.

It was interesting to notice that although the outcomes of SI were usually positive or neutral, each type also had a negative category (cf. [21-22]): eliminating information, negative dispositions to information, hiding information, non-using information, and harmful effects of information (the gray boxes in Fig. 1). These 'deviations' might make for a fruitful subject for further study. When looking back at the information element of the outcome phenomenon, the analysis made no difference between the content of information and the process of being informed (cf. "information-as-thing" vs. "information-as-process" by Buckland [59]) - as long as the information was spiritual. It would be prudent to examine this issue more closely - that is, to see if the outcomes ensuing from the information content are systematically different from the outcomes ensuing from the manner of informing. There are other relevant topics, too, which could be pursued by scholars: How do source-suggested outcomes differ from real-world outcomes? What relationships are there between the types of information outcome? What factors affect the outcomes? Furthermore, big questions such as the quantitative aspects of information outcomes, as well as the relationship between the outcomes of information and the roles of information are in need of research. These proposals are not linked to spiritual information only, but to any genre of information. Much more research is required in this area, if we are to make information and information systems more consequential.

Some unanswered questions specifically concern spiritual information: What is the significance of spiritual documents in terms of the extent of their influence? Who have published these documents? How many copies have been published, sold and distributed? How many of these documents are self- 
published? How many copies of these documents are located in public and academic libraries? What is the circulation of these documents included in library collections? What is the frequency and nature of citations and reviews of these documents? How is recorded SI different from live SI? The questions go on and on, indicating that the domain of spirituality is virtually waiting to be explored by information scientists.

\section{ACKNOWLEDGEMENTS}

I am grateful for the research grant awarded by the Finnish Academy of Science and Letters, and for the research facilities made available by my hosting university departments. Three referees contributed to the higher quality of this article, for which I thank them.

\section{REFERENCES}

[1] McCreadie M, Rice RE. Trends in analyzing access to information. Part I: cross-disciplinary conceptualizations of access. Inform Process Manage 1999; 35: 45-76.

[2] Kari J. Conceptualizing the personal outcomes of information. Information Research 2007; 12(2) [Retrieved 2008 Oct 20]. Available from: http://informationr.net/ir/12-2/paper292.html.

[3] Taylor RS. Value-added processes in information systems. Communication and Information Science. Norwood: Ablex Publishing 1986.

[4] Menou MJ, Ed. Measuring the impact of information on development. Ottawa: International Development Research Centre 1993.

[5] Hektor A. What's the use? Internet and information behavior in everyday life (Linköping Studies in Arts and Science 240). Linköping: Linköpings Universitet 2001

[6] Nicholas D, Huntington P, Williams P, Blackburn P. Digital health information provision and health outcomes. J Inf Sci 2001; 27(4): 265-76.

[7] Leckie GJ, Pettigrew KE. A general model of the information seeking of professionals: role theory through the back door? In: Vakkari P, Savolainen R, Dervin B, Eds. Information seeking in context: proceedings of an international conference on research in information needs, seeking and use in different contexts, London: Taylor Graham 1997; pp. 99-110.

[8] Rieh SY, Belkin NJ. Understanding judgment of information quality and cognitive authority in the WWW. Proceedings of the ASIS Annual Meeting 1998; 35: 279-89.

[9] Zaltman G. Construing knowledge use. In: Holzner B, Knorr KD, Strasser H, Eds. Realizing social science knowledge - the political realization of social science knowledge and research: toward new scenarios. A symposium in memoriam Paul F. Lazarsfeld (IHSStudies 3), Wien: Physica-Verlag 1983; pp. 236-51.

[10] Kari J. Seeking information on the paranormal in everyday life part I: a survey on needs and seeking of paranormal information in the framework of everyday life information seeking [in Finnish]. Master's thesis. Tampere: University of Tampere 1996.

[11] Kari J. A review of the spiritual in information studies. J Document 2007; 63(6): 935-62.

[12] Bertrand D. The therapeutic role of Khmer mediums (kru borameï) in contemporary Cambodia. Ment Health Religion Cult 2005; 8(4): 309-27.

[13] Dein S, Littlewood R. The voice of God. Anthropol Med 2007; 14(2): 213-28

[14] Drewry MDJ. Purported after-death communication and its role in the recovery of bereaved individuals. PhD dissertation. [Encinitas]: California Institute for Human Science 2003.

[15] Walter T. Mediums and mourners. Theology 2007; CX(854): 92100 .

[16] Kari J. Informational uses of spiritual information: an analysis of messages reportedly transmitted by extra physical means. J Inf Sci 2009; 35(4): 453-68

[17] Larsen JK. Knowledge utilization: what is it? Knowledge: Creation Diffusion Utilization 1980; 1(3): 421-42.

[18] Larsen JK. The nature of information utilization in local organizations. In: Holzner B, Knorr KD, Strasser H, Eds. Realizing social science knowledge - the political realization of social science knowledge and research: toward new scenarios. A symposium in memoriam Paul F. Lazarsfeld (IHS-Studies 3), Wien: PhysicaVerlag 1983; pp. 311-26.

[19] Kari J. Information seeking and interest in the paranormal: towards a process model of information action (Acta Universitatis Tamperensis 826). PhD dissertation. Tampere: University of Tampere 2001.

[20] Al-Fedaghi S. Conceptualizing effects and uses of information. In: Maceviciute E, Ed. ISIC 2008 - Information Seeking in Context: conference material, Vilnius: Vilnius University 2008; pp. 43-54.

[21] Dervin B. What methodology does to theory: Sense-Making methodology as exemplar. In: Fisher K, Erdelez S, McKechnie L(EF), Eds. Theories of information behavior (ASIST Monograph Series), Medford: Information Today 2005; pp. 25-9.

[22] Dervin B. On studying information seeking methodologically: the implications of connecting metatheory to method. Inform Process Manage 1999; 35(6): 727-50.

[23] Nicholas D, Huntington P, Williams P. Searching intention and information outcome: a case study of digital health information. Libri 2001; 51: 157-66.

[24] Wilson T, Walsh C. Information behaviour: an inter-disciplinary perspective. Sheffield: University of Sheffield 1995.

[25] Audunson R. Can institutional theory contribute to our understanding of information seeking behaviour? In: Wilson TD, Allen DK, Eds. Exploring the contexts of information behaviour: Proceedings of the second international conference on research in information needs, seeking and use in different contexts, London: Taylor Graham 1999; pp. 67-81.

[26] Rich RF. Measuring knowledge utilization: processes and outcomes. Knowl Policy 1997; 10(3): 11-24.

[27] Roland DR. Interpreting Scripture in contemporary times: a study of a clergy member's Sense-Making behavior in preparing the Sunday sermon. PhD dissertation. Emporia: Emporia State University 2007.

[28] Drewes AA. Dr. Louisa Rhine's letters revisited: the children. J Parapsychol 2002; 66(4): 343-70.

[29] Brown MF. Tsewa's gift: magic and meaning in an Amazonian society (Smithsonian Series in Ethnographic Inquiry). Washington: Smithsonian Institution Press 1985.

[30] Decuypere J-M. Channelling - sick or scientific? J Soc Psychical Res 1999; 63(856): 193-202.

[31] Tumminia DG. When prophecy never fails: myth and reality in a flying-saucer group. New York: Oxford University Press 2005.

[32] Miles MB, Huberman AM. Qualitative data analysis: an expanded sourcebook, 2nd ed. Thousand Oaks: Sage 1994.

[33] Tolvanen T, Hartonen M. Northern light: Antero Vipunen [in Finnish]. Savonlinna: Mauri Hartonen 1998.*

[34] Fagerström R. Time for a radical change [in Finnish]. Helsinki: Aquarian Publications 1993.*

[35] Laaksonen L. Enoch's book of knowledge 1 [in Finnish]. Helsinki: Kustannus Oy Taivaankaari 1993.*

[36] Denah, Zudu. Message to humankind V [in Finnish]. No publisher 1989.*

[37] Korso Triangle's questions and answers 4/4/95 [in Finnish]. Valonkantajat [Bearers of Light] 1995; (5): 19-23.*

[38] Riikonen L. From rainbow to reality [in Finnish]. Helsinki: Kustannus Oy Taivaankaari 1993.*

[39] Raunio S. The key to the realm of angels [in Finnish]. Laitila: Laitila Printing House 2006.*

[40] Hesekielin työryhmä [Ezekiel's Work Group]. Words of wisdom [in Finnish]. Valonkantajat 1993.*

[41] Korhonen M. Teachings of the Galactic Federation to Earth humans [in Finnish]. Lahti: Henkinen Tiede ja Elämä 1997.*

[42] Riikonen K. Universal teachings on the cosmos [in Finnish] Jyväskylä: Tähtitieto 1993.*

[43] Turunen R. Guidance of love [in Finnish]. No publisher 2005.*

[44] Mäkinen S. A devilishly good letter from divinity [in Finnish] Turku: Senid Teollinen muotoilu 2004.*

[45] Tolvanen T, Hartonen M. Sampo of spiritual treasures: the words were uttered by Väinämöinen [in Finnish]. Savonlinna: Mauri Hartonen 1999.*

[46] Laaksonen S, Ed. Letters about life from beyond the borderline of death [in Finnish] 2nd ed. Porvoo: Revelation 1971.*

[47] Fagerström R. The gate after life: messages by automatic writing [in Finnish]. Helsinki: Aquarian Publications 1991.* 
[48] Raunio S. Pekka's story from life to death and from death to life [in Finnish]. Laitila: Laitila Printing House 2004.*

[49] We're messengers of the White Brotherhood [in Finnish]. Author 2003.*

[50] Hesekielin työryhmä [Ezekiel's Work Group]. Rays of light [in Finnish]. Valonkantajat 1993.*

[51] Hedman S. A greeting from the Great White Brotherhood [in Finnish]. Minä Olen [I Am] 2005; (3): 54-55.*

[52] Vuorinen V. Life is a gift: be aware of the freedom and possibility of development granted to you as life's great riches [in Finnish]. Jyväskylä: Vesa Vuorinen 1998.*

[53] Zudu D. Message to humankind III [in Finnish]. No publisher 1988.*

*These texts belong to the empirical data
[54] A sinner's confession: written by a disciple according to Homo's dictation [in Finnish] (Messages from the Spiritual World V). Hyvinkää: Hyvinkää Printing House 1945.*

[55] Humanoid from a Jupiter moon. Life in the universe: a Finnish contact in 1970-72 [in Finnish]. Helsinki: Mysteeni 1973.*

[56] The Goddess' heralds and the mer-ka-ba triangle vessel [in Finnish]. Earth Chambers 2007 [Retrieved 2007 Jul 19]. Available from: http://www.earthchambers.com/main.htm.*

[57] Moilanen J. We're forever one: messages from our Creator [in Finnish]. Kirkkonummi: Kustannus Oy Taivaankaari 2000.*

[58] Peltola M. Kryon's Christmas message 17/12/2005 [in Finnish]. 2005 [Received 2005 Dec 21]. Available from: mika.el[at]kolumbus.fi.*

[59] Buckland MK. Information as thing. J Am Soc Inf Sci 1991; 42(5): $351-60$.

Received: March 30, 2010

(C) Jarkko Kari; Licensee Bentham Open.

This is an open access article licensed under the terms of the Creative Commons Attribution Non-Commercial License (http://creativecommons.org/ licenses/by-nc/3.0/) which permits unrestricted, non-commercial use, distribution and reproduction in any medium, provided the work is properly cited. 